\title{
Environmental Assessment and Health Impact Assessment
}

Salim Vohra, Marla Orenstein, Francesca Viliani, Ben Cave, Ben Harris-Roxas and Filipe Silva

Current Word Count: 6571 including references and 2 figures (Limit 6000 words and 3 figures including references)

\section{Salim Vohra}

Lecturer in Health Promotion and Public Health

College of Nursing, Midwifery and Healthcare

University of West London, UK

Marla Orenstein

Director

Habitat Health Impact Consulting, Canada

Francesca Viliani

Head of Public Health Consulting Services and Community Health Programs

International SOS, Denmark

Ben Cave

Director

Ben Cave Associates, UK

Ben Harris-Roxas

Deputy Director

Centre for Health Equity Training Research and Evaluation, Australia

Filipe Silva

Director

Public Health by Design, UK 
Environmental Assessment and Health Impact Assessment

Abstract

Systematically and holistically considering the community health impacts of new policies and projects is critical. Impact assessment (IA) is a key component of national, international and many commercial policy and project development and decision-making processes. Health impact assessment (HIA) and the health component of environmental assessment (Health in EA) analyses both the potential positive and negative health impacts of policies and projects. HIA and health in EA by engaging stakeholders and incorporating a range of sources and types of evidence can maximise the positive and minimise the negative impacts. This means that precautionary principle is implicitly or explicitly a part of the IA process. There are a range of significant challenges in applying IAs and in applying the precautionary principle, particularly in the IA process. Public health professionals need to engage in the IA process, in HIAs and in Health in EAs, to protect and promote community health and wellbeing.

\section{Keyword}

Health impact assessment, HIA, environmental assessment, EA, precautionary principle, community health, decision-making, project development, policy development, public health 


\section{Environmental Assessment and Health Impact Assessment}

Salim Vohra, Marla Orenstein, Francesca Viliani, Ben Cave, Ben Harris-Roxas and Filipe Silva

\section{The role of impact assessment}

Impact assessment is the name given to a range of systematic approaches and methodologies. Its purpose is to identify the future consequences of, and make recommendations to strengthen, a proposed project, programme, plan or policy. Impact assessment can look at effects ranging from social, cultural, economic and health effects to effects on the physical environment. These consequences can be either positive or negative; intended or unintended.

Impact assessments are often conducted as part of a policy development or regulatory process in order to inform decision-makers about whether and how a project, programme, plan or policy should be implemented. For example, a company may submit a proposal to government to explore for natural gas near a national park, or near a town or city, using hydraulic fracturing (fracking) methods. An impact assessment would identify the likely potential effects of the development on local ecosystems including flora, fauna, air, water and soil. It would also identify how the project could affect social conditions, economic opportunities and health status of human populations. And finally, it would suggest recommendations to avoid or minimise potential harms from the project. Another example, focusing on review of a policy rather than a project, could be the assessment of a local greenspace strategy or the strategic redevelopment of unused green spaces in a district for private housing [City of London, 2014; Palerang Council et al, 2006].

As indicated above, impact assessments identify and prioritise potential effects (impacts) of a project or policy proposal, as well as recommend mitigation and enhancement measures. These measures may focus on how the design of the proposal could be improved, or how best it could be implemented to avoid or minimise harms and maximise benefits. Examples of mitigations include: minimising air emissions through the use of alternative technologies that reduce air emissions at source; suggesting how local hiring could be undertaken so that affected communities can also benefit from a proposal; or outlining how agricultural land and natural spaces could be protected and enhanced as part of a housing development or a transport strategy. 
While impact assessments characterise effects and develop potential mitigation and enhancement measures, these assessments do not comprise decision-making itself. Rather, a decision-making body such as a regulatory authority, permitting authority or government (local or national) will take the results of the impact assessment under advisement when making a decision about whether or how to allow the proposed project or policy to proceed.

Impact assessments are prospective, meaning they are undertaken when a proposal is being developed and before it is implemented, as this is the time where there is the greatest scope for changes to be easy to make to a proposal. Even so, for an impact assessment to influence decision-making, the commitment of decision-makers to implement recommendations and the timing of the assessment in relation to the wider social and economic environment are crucial.

This chapter focuses on two broad types of impact assessments relevant to public health: environmental assessment (environmental impact assessment and strategic environmental assessment) and health impact assessment (HIA). ${ }^{1}$ Environmental assessment (EAs) and HIA approaches, and processes, can help to protect and enhance public health by:

- critically analysing proposals,

- analysing how the proposals are likely to be implemented, and

- examining how the proposals are likely to be operationalised in real-world contexts.

The best assessments bring people together: proponent, decision-makers, communities, academia and other stakeholders. The process therefore should be rigorous and scientific and, at the same time, encourage the participation of stakeholders with different competencies and interests. This requires a multidisciplinary team that has community and stakeholder engagement skills, communication skills, as well as technical subject-specific assessment expertise. A well-conducted impact assessment can help to foster working relationships between organisations and develop a consensus on shared priorities. Public health professionals and the health sector in general therefore need to understand, engage with, and participate in both EAs and HIAs. By not doing so they abdicate responsibility to other groups

\footnotetext{
${ }^{1}$ Health impact assessment can often be stated as human health impact assessment or community health impact assessment to identify that the focus is on humans rather than the health of flora and fauna. In this chapter the discussion of health is related to the health and wellbeing of individuals and groups in human communities and settlements.
} 
who quite reasonably focus on their own priorities at the expense of public and environmental health issues.

\section{Environmental impact assessment}

Environmental impact assessment (EIA) is the oldest and most established form of impact assessment. The requirement for EIA was originally mandated in the United States in 1969, with the passing of the National Environmental Policy Act (NEPA). This was an important landmark for EIA as it influenced the development of similar requirements in most other countries in the world [Alma, 1988].

One of the simplest definitions of EIA is that it is "an assessment of the impacts of a planned activity on the environment" [United Nations Economic Commission for Europe, 1991]. A more nuanced definition is that: "... EIA is a ... systematic process that examines the environmental consequences of development actions, in advance. The emphasis, compared with many other mechanisms of environmental protection, is on prevention. Of course planners have traditionally assessed the impacts of developments on the environment, but invariably not in the systematic, holistic and multidisciplinary way required by EIA" [Glasson, et al, 2005, p. 3].

EIAs generally focus on potential effects across the following topic areas: water, air and soil quality/quantity; flora and fauna; archaeology and heritage; noise; landscape and visual amenity; and socio-economic environments. The core steps of the process are shown in Figure 1. 
Figure 1: Core steps of the EIA process [Adapted from Morris and Therivel, 2001]

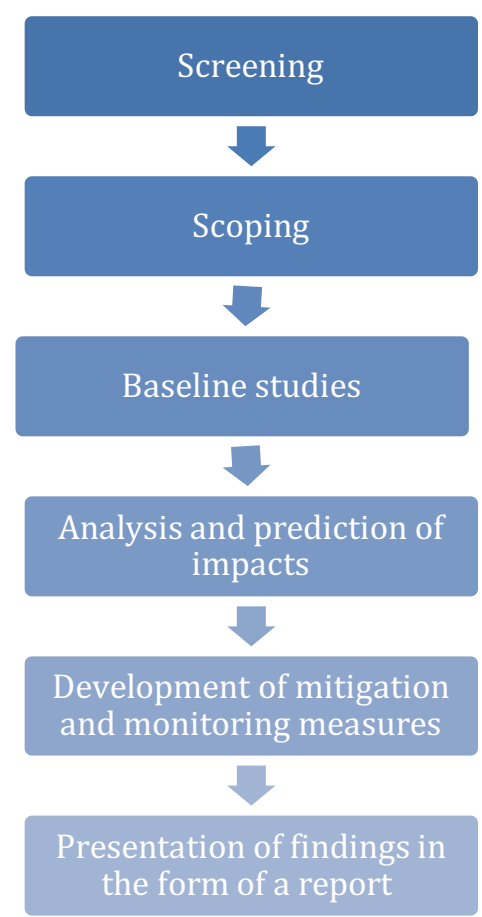

The requirements for conducting EIA are embedded within the laws and regulations of national and cross-country authorities. Although the main intent of identifying and mitigating in advance the potential adverse environmental consequences of a planned action, is the same, procedural elements vary across jurisdictions.

Though EIA encompasses impacts on human populations, the way in which health has been approached in EIAs ${ }^{2}$ has traditionally been very narrowly defined as the potential for negative impacts on biophysical health outcomes [Harris et al, 2015]. This is often specifically framed in terms of the hazards and risks of exposure to chemicals in the air, water or soil that are associated with a project. As will be discussed later, this narrow focus within EIA was one of the reasons for the rise and development of HIA in some countries (and social impact assessment, SIAs, in others) [Kemm et al, 2004; Dendena and Corsi, 2015].

Some countries, international lending institutions, international industry sector associations, and transnational businesses, have either mandated or recommended that EIAs have strong

\footnotetext{
${ }^{2}$ Health component is used here to mean the whole range of assessments that consider human health and include elements such as the air quality assessment, land contamination assessment, water quality assessment and socio-economic assessment as well as a health impact assessment that considers the implications of changes to the social environment because of a proposal.
} 
social and health components [Harris-Roxas et al, 2012]. These assessments are often described as Environmental, social and health impact assessments (ESHIAs). ESHIAs are part of a family of assessments called integrated impact assessments (IIA) or integrated assessments (IA) because they bring together separate types of assessments in order to produce a more integrated understanding of the potential impacts, an integrated set of mitigation and enhancement measures, and an integrated set of monitoring indicators. (Bond et al. 2001; Milner et al, 2005).

\section{Strategic environmental assessment}

The term 'EIA' is generally reserved for the assessment of projects. When the same type of analysis is conducted on strategies, plans or programmes - such as an open space strategy or an oil and gas leasing programme - the term 'Strategic Environmental Assessment' (SEA) is applied. SEA is most often undertaken or commissioned by national or local governments, because these are the entities that are concerned with the types of wide-ranging future strategies or policy actions that SEA assesses.

For example, an SEA would assess whether the vision and objectives of the policy are sound from an environmental, social, economic and health perspective; what criteria should be used to decide on where future developments should be situated; what green and blue spaces would be 'no go' areas for development, and the kinds of approaches and technologies that should be considered by any future development in order to protect human health and the environment. The SEA helps to ensure that the strategy is sound from an environmental, social and health perspective. An example of this is an SEA for an open space strategy [Dumfries \& Galloway Council, 2014].

Only after the SEA has assessed a policy or strategy would an EIA then be conducted, on a case-by-case basis, as proposals come forward seeking approval from decision-makers to implement specific projects within the policy or strategy boundaries. An example of this is a transport strategy which sets out a vision for an updated transport system involving a rapid bus transit scheme, a road bypass or a new rail scheme. Only after the SEA is completed on the transport strategy, and the transport system, would an EIA be undertaken on the outline or detailed plans of the rail scheme. 


\section{Health impact assessment}

A widely accepted definition of HIA is that: "Health impact assessment may be defined as a combination of procedures, methods and tools that systematically judges the potential, and sometimes unintended, effects of a policy, plan, programme or project on the health of a population and the distribution of those effects within the population. HIA identifies appropriate actions to manage those effects" [Quigley et al, 2006, p. 1].

HIA has developed from three main strands of thinking (and their associated frameworks and processes) [Kemm et al, 2004]:

1. Epidemiological and quantitative health risk assessment;

2. Healthy policy and health promotion; and

3. Social determinants of health.

\section{From risk to impact}

Starting the 1950s, developments in epidemiology led to approaches that quantified the potential adverse impacts of exposure to man-made chemicals in the air, water, soil and food. These approaches, and associated methodologies, are known as health risk assessment. From the 1970s and 1980s, the healthy public policy and health promotion movements recognised that promoting health and preventing ill health were as important as treating disease, and that health and wellbeing were not just about good quality healthcare. They were also about good quality and affordable access to the natural environment, housing, education, transport networks, and public and private goods and services. From the 1980s and 1990s, there was a growing recognition of the need to incorporate the social determinants of health into EIA. This was accompanied by two realisations. Firstly, the limited value of the health risk assessment approach used in most EIAs. Secondly, the need to address, and promote, more equitable social and health outcomes [Harris-Roxas and Harris, 2011].

HIA is undertaken in many countries around the world, though it has not been embedded in regulatory processes to the same extent as EIA. Several countries have adopted requirements for stand-alone HIA; some have endorsed better consideration of health in their national EIA processes; while others have developed national-level guidance on undertaking HIA or better considering health in EIA [Winkler et al, 2013; Ross et al, 2014; Fehr et al, 2014]. 


\section{Steps for HIA}

The steps of an HIA are similar to EIA and are described in Box 1 [Birley, 2011].

\section{Box 1: The key steps in a Health Impact Assessment Process}

Screening: Deciding if a proposal could generate potential health consequences and whether a HIA should be undertaken.

Scoping: Setting the scope of the impact assessment by identifying the potential health impacts of concern, what issues do not need to be considered, what sources and types of evidence will be considered, what qualitative and quantitative methods will be used, whether there will be an expert steering or advisory group, and what the assessment's temporal, spatial and population boundaries will be i.e. what time period, geographical area and communities, and population sub-groups, will be considered in the assessment. The findings and judgments made during scoping will be written up either as a Scoping Report or a Terms of Reference for the HIA.

Baseline assessment or community profile: Collecting and analysing a range of desktop and fieldwork information to understand the existing health and wellbeing status of the affected populations and the current state of the environmental and social determinants of health influencing them. This provides the baseline from which predictions on possible and likely health impacts are made. Information types that are used include demographic, health, environmental and socioeconomic statistics; scientific and other credible literature on health impacts; existing policies; expert opinion; and community feedback and other stakeholders' views, including public health practitioners and healthcare providers.

Impact analysis: Identifying, characterising, assessing the significance of and prioritising the potential health and wellbeing impacts.

Formulating recommendations: Developing feasible mitigation and enhancement measures to minimise the potential negative impacts and maximise the potential positive impacts. These measures are written up can be written up in a separate impact management plan.

Decision and subsequent implementation: The authority responsible for the HIA process will decide whether a proposal goes ahead and if it goes ahead what changes need to be made to the proposal based on the recommendations of the HIA. The proponent of a proposal will take responsibility for ensuring that the impact management plan is implemented alongside the implementation of a proposal. 
Follow up: Monitoring and evaluation of both the implementation of a proposal and, less often, the HIA process.

The findings of stakeholder engagement and consultation should inform the HIA process and its findings. Many guides recommend stakeholder engagement and consultation be undertaken at all steps of the HIA process. More often than not consultation is undertaken at one or two points in time: during scoping and during the analysis steps.

The above description of the steps of HIA makes it look like a linear process but, in reality, the process is more iterative i.e. as changes to the design of the proposal are occurring the scope of the assessment, the baseline information that is needed and the findings of the preliminary analysis have to be reviewed and revised.

HIA has an explicit set of values that frame the HIA process. These values are that the HIA be: democratic and participatory; equitable, sustainable, transparent, and ethical in the use of evidence [European Centre for Health Policy and World Health Organization Regional Office for Europe, 1999; Bhatia et al, 2014; Martuzzi et al, 2014]. One additional underlying value of HIA is that the maximisation of health opportunities for all is an important societal good and a priority societal goal [Hurley and Vohra, 2010]. Health impacts are contextual and are linked to a specific natural and socio-economic environment. HIA, like EIA, therefore aims to develop a set of evidence-based, locally-implementable, legislatively-appropriate and culturallyrelevant recommendations for dealing with the potential impacts that are identified.

A key feature of HIA is that it considers both positive and negative impacts on community health and wellbeing. This is different than EIA, which generally only considers potential adverse effects. HIA systematically considers a wide range of environmental and social determinants of health as shown in Figure 2. Those impacts may be direct or indirect. Direct impacts are those generated by a project and its activities e.g. traffic injuries from lorries going to and from a project or changes in employment status from the provision of project-related jobs. Indirect impacts are those which occur as a result of the project changing other social, economic and cultural factors; e.g., an increase in demand for local goods and services leading to a rise in local prices and resultant food insecurity or housing affordability. Not all determinants apply in all cases; each HIA will focus on those determinants most likely to be affected by the proposed project or policy. 
Figure 2: The wider environmental and social determinants of health and wellbeing [Vohra, 2008]

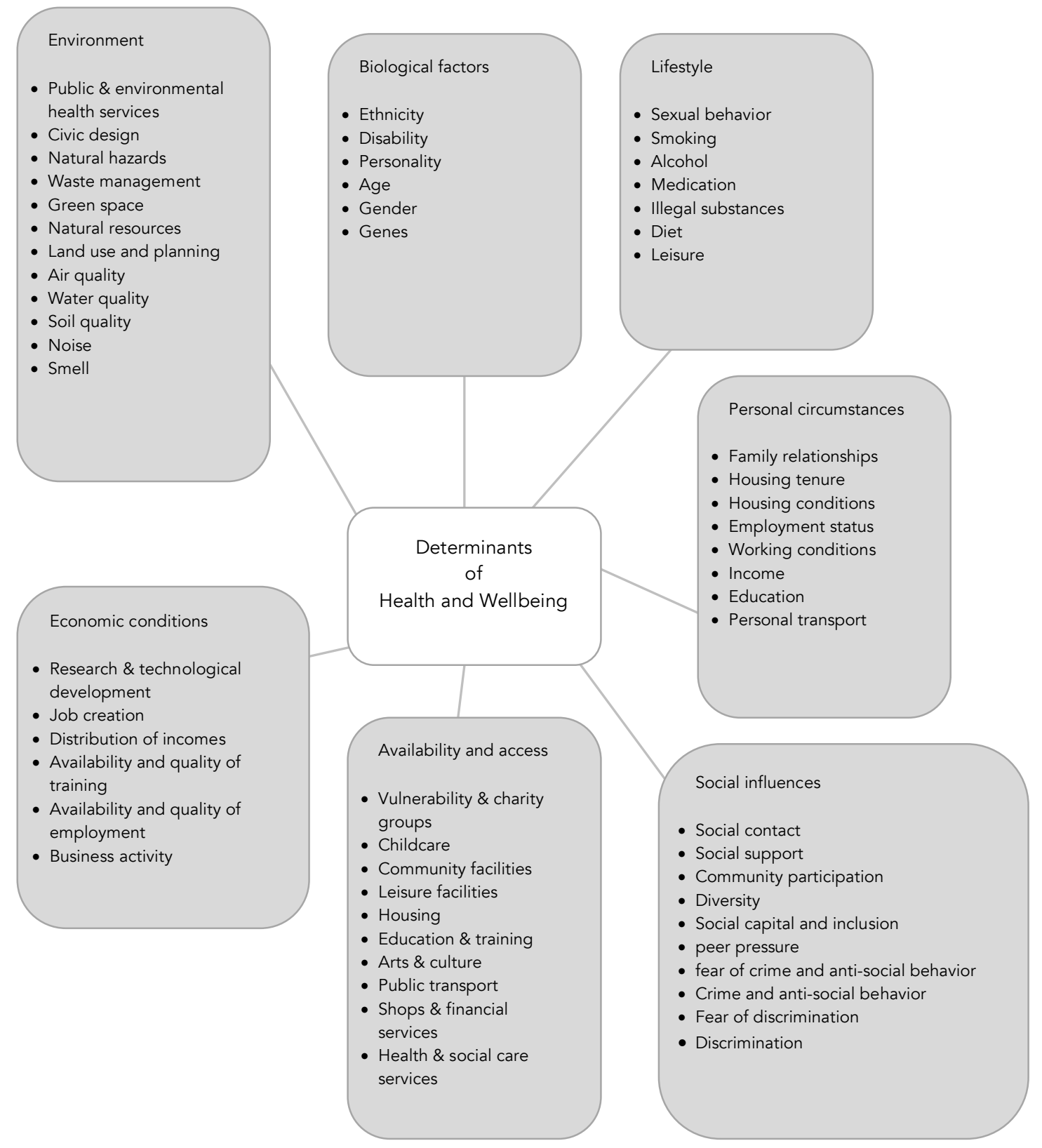


To give a sense of the types of issued examined in an HIA and the types of recommendations that may be made, Boxes 2 and 3 present a high-level summary of two HIAs that were undertaken on greenspace project proposals. Although the findings and recommendations presented may appear somewhat self-evident to those familiar with the determinants of health, they highlight the way in which HIA can be a useful approach and process to systematically bring forward health-related issues into decision-making processes that would not otherwise consider health. 
Box 2: A HIA of park, trail, and green space planning in the west side of Greenville, South Carolina, USA [South Carolina Institute of Public Health, 2013]

This HIA was undertaken by the South Carolina Institute of Medicine and Public Health to inform urban and greenspace planning in three economically depressed and physically fragile neighbourhoods on the west side of Greenville, South Carolina. The HIA focused on six priority areas: physical activity, social cohesion/capital, community and family economic stability, food access, individual and community safety and air and water quality.

The HIA concluded that the park had the potential to increase physical activity, leading to an improvement in mental and physical well-being and addressing the high obesity and chronic disease rates in the community. The HIA also found that the proposed park would increase social cohesion among residents by providing a venue for residents to gather.

The HIA made a number of specific recommendations to the City to support positive health during the park development process. These recommendations included the following:

- $\quad$ provide opportunities to walk and bike to and from the potential new park (e.g. sidewalks and bike lanes as well as good signage and community education),

- provide access to healthy and affordable food sources (e.g. community garden and/or farmer's market in the potential new park)

- $\quad$ provide opportunities for interaction between community members (e.g. community garden and/or event space in the park)

- $\quad$ provide safe paths and signs to encourage utilisation of the potential park (e.g. connection from the west side to potential new park, signage in English and other languages)

- $\quad$ provide opportunities to strengthen the relationship between the potential new park and the surrounding community (e.g. integrate history and culture of local community in the design of the potential new park, encourage partnerships with local artists)

- provide opportunities to improve mental health of community residents (e.g. design in places for relaxation and meditation, such as open green space with benches and swings). 
Box 3: A HIA of the Garden City Project in Yala City, Thailand [Thailand Department of Health, 2004]

This HIA was undertaken by the Thailand Ministry of Public Health. The city of Yala, is a Buddhist-Muslim community in the south of Thailand. The Yala Garden City Project is an on-going effort intended to make Yala City a healthy place to live and to provide a learning environment for residents. As part of the project, $19 \mathrm{~km}^{2}$ of space in various municipal areas have been developed as gardens, parks and green areas surrounding the city. Five sub-projects including gardens and parks for different functions such as recreation, exercise, and social activities have been completed and opened to the public. The HIA hypothesized that the "Garden City" approach would have various impacts on the health of individuals, families, and the community at physical, psychological, social, and spiritual levels. The HIA used participatory action research to provide recommendations to the local authority, the Yala Municipality, for further increasing the positives and reducing the negative impacts of the project.

The HIA used a variety of methods to understand how the Garden City project was influencing the health of local community members, including a survey of park users, food and drink vendors and local residents; observations of park use; and interviews with key authorities.

The HIA found that the Garden City Project had a number of positive health impacts. The gardens provided recreation areas for outdoor activities and exercises, beautiful scenery in the city, and among the residents of Yala City, it enhanced the sense of security and care by the local government. Local people reported an increase in physical strength and a decrease in fatigue, as well as an increase in joyfulness and a reduction in irritation. In terms of social health, local people identified were that there were more opportunities to join with friends and to see other people. However, the HIA did not find a quantitative change in rates of participation in social activities held in the parks and gardens, and there was no change identified in objective measures such as the use of routine medication and the frequency of visits to primary care.

This HIA reinforced for the decision-maker-in this case the municipality-that investments that were made in improving the physical environment could simultaneously result in improved health and well-being for the local population. As a result, the policy makers have taken the public recommendations for project development into account and assigned responsible authorities for implementation. In addition, local experts and specialists formed a multidisciplinary research and development network to continue impact assessments for the sustainable development of local public health policy. 


\section{Impact assessment and decision-making}

Impact assessment fits into the broader evidence-based policy movement. Hence, the general consensus is that the purpose of impact assessment is to support policy and decision-making in institutions such as national and local governments, private sector businesses, and international lending agencies and institutions [Senécal et al, 1999; International Finance Corporation, 2012 and 2009; International Council on Mining and Metals, 2010].

Impact assessments often generate a range of expectations and aspirations that the impact assessment practitioner, team or advisory committee needs to take into account and manage [Kemm, 2000; Peterson, 2004; LaBouchardiere et al, 2014].

The legislative mandate under which EIA operates means that EIA has become part of the accepted process by which policies, plans, programmes and projects are permitted. This in turn has ensured that, to varying degrees, most countries and key international institutions have an institutional infrastructure for EIA. In most countries around the world, HIA does not enjoy a legislative mandate similar to that of EIA. This in turn means that there is often an associated absence of institutional infrastructure for HIA ranging from an absence of accepted forms of practice, mechanisms for assuring quality and pathways for educating public health, environmental and planning professionals in HIA.

A review of voluntary and regulatory approaches to HIA at the national, subnational and international levels concluded that there is considerable untapped potential for HIA to be used more widely and effectively [Winkler et al, 2013].

Methodological challenges to the development of HIA include questions about its usefulness, the evidence and frameworks that it uses, and the values that inform an assessment of health and well-being [Cashmore et al, 2004; Parry and Stevens, 2001; Krieger et al, 2010, Vohra et al, 2010]. Scrutiny and review is welcomed and is an essential way of improving HIA. However, critics often overlook the value HIA provides and the constraints under which it operates. HIA practitioners are advocating for health and wellbeing outside the health sector and would benefit from the support as well as the critique of their peers. HIA is a pragmatic approach and uses a range and sources of evidence. For health impacts caused by biophysical changes, such as air pollution, there is epidemiological evidence that can help with the identification and quantification of health impacts for a specific intervention. For health impacts caused by social or political changes the relationship is more complex or less amenable to focusing on 
the particular effects of a single policy or project. In particular, there is a lack of evidence on the efficacy of intervention on the social determinants of health in real-world contexts.

The process of impact assessment involves engaging a range of stakeholders in discussion and negotiation [Birley, 2010]. Stakeholders usually include, as a minimum, the proponent, the policy development or decision-making authority and communities. It is also a process of applied science that uses best available evidence, a systematic and transparent approach to reduce bias, a range of sources of evidence, and a variety of qualitative and quantitative methods of prediction to ensure that the findings are as accurate as they can be [Hurley and Vohra, 2010].

The success or the effectiveness of an HIA can occur at two broad levels [Quigley and Taylor, 2004]. Firstly, successfully altering a specific proposal so that it is more likely to improve community health outcomes, reduce inequalities and enhance equity. Secondly, helping to build health partnerships and relationships; for example, fostering interagency working relationship or increasing the visibility of health in the political agenda [Haigh et al, 2015]. This is most likely to happen when the experts and practitioners involved are pragmatic, tactical and technical [Harris et al, 2014].

By reviewing past HIA reports and processes, researchers have developed a series of recommendations to make HIA more effective [Haigh et al, 2015; Bourcier et al, 2015]:

- Consider if HIA is the right process for the proposal to be examined in the early phases;

- Clarify early in the process: purposes, goals, values and expected outcomes;

- Select an appropriate team to conduct the HIA with a mix of competences; as well as identify key stakeholders and their relative points of influence within policy development and decision-making processes;

- Involve stakeholders as early as possible;

- Ensure HIA processes include potentially affected communities and pay attention to the needs of vulnerable sub-groups;

- Craft clear, actionable recommendations, with the support of the involved decisionmakers, affected stakeholders and the proponent of the proposal; 
- Be both technical and tactical: understand the context and the actors, proactively engage, and where needed utilise a more flexible though still structured HIA process.

\section{Impact assessment, health, and the precautionary principle}

There are two broad formulations of the Precautionary Approach or Principle (Ahteensuu, 2007). The first is the 1992 Rio Declaration on Environment and Development. This states that: "In order to protect the environment, the precautionary approach shall be widely applied by States according to their capabilities. Where there are threats of serious or irreversible damage, lack of full scientific certainty shall not be used as a reason for postponing costeffective measures to prevent environmental degradation" (United Nations, 1992, Principle 15). The second is the 1998 Wingspread Statement. This states that: "When an activity raises threats of harm to human health or the environment, precautionary measures should be taken even if some cause and effect relationships are not fully established scientifically" [Science and Environmental Health Network et al, 1998]. The latter is a more proactive definition advocating action to minimise harm. The Wingspread Statement also puts the burden of proof on the proponent of a proposal. It advocates that the process of applying the principle must be open, informed, democratic, include potentially affected parties and involve reviewing the full range of alternatives, including not taking any action. The statement closely echoes the values that are embedded within impact assessment and HIA especially.

In relation to applying the precautionary principle, environmental health regulatory systems, generally make a determination on a potential threat, the 'reasonable grounds for concern', based on preliminary scientific assessments that provide information and evidence of the potential for something being a hazard to the environment or human, animal, and plant health [European Commission, 2000; Martuzzi and Tickner, 2004]. Environmental, social and health impact assessments can be seen as a form of 'preliminary assessment'.

Impact assessments are inherently precautionary because they assess and recommend measures to reduce harm and, wherever possible, enhance benefits. They do so in a context of uncertainty in relation to baseline information on the status of affected communities and natural environments, both in the present and over the life of a proposal. They consider both how a proposal will be implemented and how the proposal is likely to operate over its life. Most importantly, they examine who is likely to be worst affected, as well as how and when. High-quality impact assessments gather the best available information and evidence within time and resource constraints, address uncertainty clearly, consider worse case scenarios, and 
develop mitigation measures to enable these worse case scenarios to be minimised. They also leverage opportunities to enhance, maximise and equitably share out the beneficial impacts to all the communities that are involved or affected.

However, there are challenges in applying the precautionary principle because different stakeholders and some proponents, whether governments or businesses, can frame the impact assessment, and the policy and decision-making process in ways that preclude the use of the precautionary principle to its fullest extent. A key issue is the defensibility of predictions and statements made in an impact assessment in judicial and quasi-judicial settings. This is particularly the case in the following three contexts [European Commission, 2000; Martuzzi and Tickner, 2004; Hardstaff, 2000]:

- Where there is a lack of, or inconclusive, evidence for an impact that is theoretically possible;

- Where there is no scientific consensus on the causal mechanism for the impact; and

- Where there the likelihood of the impact occurring cannot be qualitatively or quantitatively estimated.

Deciding when and how to invoke the precautionary principle is also not straightforward. An example of this are the opposing views on the potential environmental and health impacts from projects using high-volume hydraulic fracturing (fracking) for the extraction of natural resources [Kovats et al, 2014; Cotton, 2015]. International opinion is divided not only between project proponents and communities, but also between national and state governments in different countries (and even within the same country). The scientific evidence is also not clearcut. Some jurisdictions have allowed extensive use of this technology [California Fracking, 2016]. Others have mandated a moratorium until further research is undertaken, the potential impacts associated with this technology are sufficiently understood, and a satisfactory regulatory framework is in place [Scottish Government, 2015; Keep Tap Water Safe, 2016].

Ultimately, the precautionary principle needs to be embedded in, and be a part of, policy and decision-making processes for its use to be fully effective within impact assessment. This is because, as stated in the previous section ('Impact assessment and decision-making'), impact assessments most often support and inform the decision-making process and advise how to improve the design of a proposal rather than finding for, or against, a particular decision. 


\section{Conclusion}

HIA and EA are approaches and processes that support better, healthier and more sustainable policy development and decision-making. When undertaken well, and when valued and applied, they can also help to support better, more informed, transparent and democratic policy development and decision-making processes. However, they are not a panacea; rather, they constitute one important piece of the policy development and decision-making puzzle.

Public health practitioners need to increase their knowledge and understanding of EA and HIA. They should improve their links with EA and HIA specialists. They also need to proactively and consistently undertake and commission assessments of health either within EA or as standalone HIAs. Public health practitioners would also do well to oversee and scrutinise the scope of work for, and the findings of, EAs and HIAs that are commissioned and undertaken by others in the localities in which they work. By doing so, public health practitioners can help to advance the agenda of improving health for all by acting on the upstream determinants of health and bringing together key actors across society. 


\section{References}

Ahteensuu, M. (2007) 'Rationale for taking precautions: normative choices and commitments in the implementation of the precautionary principle', SCARR (Social Contexts and Responses to Risk) Risk \& Rationalities, Queens' College, Cambridge, 29-31 March 2007. Available at: https://www.kent.ac.uk/scarr/events/ ahteensuu.pdf (accessed 1 June 2017) [Online].

Alm A.L. (1988) 'NEPA: Past, Present and Future', EPA Journal, January/February.

Bhatia, R., Farhang, L., Heller, J., Lee, M., Orenstein, M., Richardson, M. and Wernham, A. (2014) Minimum elements and practice standards document: minimum elements and practice standards for health impact assessment. Version 3, September, 2014.

Birley, M. (2011) Health impact assessment: principles and practice. London: Earthscan.

Bond, R., Curran, J., Kirkpatrick, C. and Lee, N. (2001) 'Integrated impact assessment for sustainable development: a case study approach', World Development, 29(6), pp. 1011-1024.

Bourcier, E., Charbonneau, D., Cahill, C. and Dannenberg, A.L. (2015) 'An evaluation of health impact assessments in the United States 2011-2014', Preventing Chronic Disease,12:140376.

California Fracking (2016) Fracking in California: where is fracking occurring. Available at: http://www.cafrackfacts.org/fracking-in-california/where-is-fracking-occurring (Accessed: 01 May 2016).

Cashmore, M., Gwilliam. R., Morgan, R., Cobb, D. and Bond, A. (2004) 'The interminable issue of effectiveness: substantive purposes, outcomes and research challenges in the advancement of environmental impact assessment theory', Impact Assessment and Project Appraisal, 22(4), pp. 295-310.

City of London (2014) Draft City of London open space strategy supplementary planning document rapid health impact assessment. Department of the Built Environment.

Cotton, M. (2015) 'Stakeholder perspectives on shale gas fracking: a Q-method study of environmental discourses', Environment and Planning, 47(9), pp. 1944-1962.

Dendena, B. and Corsi S. (2015) 'The environmental and social impact assessment: a further step towards an integrated assessment process', Journal of Cleaner Production, 108, pp. 965977. 
Dumfries \& Galloway Council (2014) Dumfries and Galloway draft open space strategy SEA environmental report. Available at:

http://www.dumgal.gov.uk/CHttpHandler.ashx?id=14081\&p=0 (Accessed: 01 May 2016)

European Centre for Health Policy and World Health Organization Regional Office for Europe (1999) Health impact assessment: main concepts and suggested approach. The Gothenburg consensus paper. Brussels.

European Commission (2000) Communication from the Commission on the precautionary principle. Brussels: Publications Office of the European Union.

Fehr, R., Viliani, F., Martuzzi, M. and Nowacki, J. (2014) Health in Impact Assessments: Opportunities not to be missed. World Health Organization Regional Office for Europe, European Association of Public Health and International Association for Impact Assessment.

Glasson, J., Therivel, R. and Chadwick, A. (2005) Introduction to Environmental Impact Assessment. 2nd edn. London: University College London (UCL) Press.

Haigh, F., Harris, E., Harris-Roxas, B., Baum, F., Dannenberg, A.L., Harris, M.F., Keleher, H., Kemp, L, Morgan, R. Ng Chok, H and Spickett, J. (2015). 'What makes health impact assessments successful? Factors contributing to effectiveness in Australia and New Zealand', BMC Public Health, 15:1009.

Hardstaff, P. (2000) The precautionary principle, trade and the WTO. A discussion paper for the European Commission Consultation on Trade and Sustainable Development. Bedfordshire: Royal Society for the Protection of Birds.

Harris, P., Sainsbury, P. and Kemp, L. (2014) 'The fit between health impact assessment and public policy: Practice meets theory', Social Science \& Medicine, 108, pp. 46-53.

Harris, P., Viliani, F. and Spickett, J. (2015) 'Assessing health impacts within environmental impact assessments: an opportunity for public health globally which must not remain missed', International Journal of Environmental Research and Public Health, 12, pp. 1044-1049.

Harris-Roxas, B. and Harris, E. (2011) 'Differing forms, differing purposes: a typology of health impact assessment', Environmental Impact Assessment Review, 31(4), pp. 396-403. 
Harris-Roxas, B., Viliani, F., Bond, A., Cave, B., Divall, M., Furu, P., Harris, P., Soeberg, M. Wernham, A. and Winker, M. (2012) 'Health Impact Assessment: the state of the art', Impact Assessment and Project Appraisal, 30(1), pp. 43-52.

Health Scotland, greenspace scotland, Scottish Natural Heritage and Institute of Occupational Medicine (2008) Health impact assessment of greenspace: a guide. Stirling: greenspace scotland.

Hurley, F., and Vohra, S. (2010) 'Health Impact Assessment', in Ayres, J.G., Harrison, R.M., Nichols, G.L. and Maynard, R.L. (ed.). Environmental Medicine. London: Edward Arnold.

International Council on Mining and Metals (2010) Health impact assessment: summary of the good practice guidance. London: International Council on Mining and Metals (ICMM).

International Finance Corporation (2012) Performance standards on environmental and social sustainability. Washington: International Finance Corporation (IFC), World Bank Group.

International Finance Corporation (2009) Introduction to health impact assessment. Washington: International Finance Corporation (IFC), World Bank Group.

Keep Tap Water Safe (2016) List of bans worldwide. Available at: http://keeptapwatersafe.org/global-bans-on-fracking (Accessed: 01 May 2016).

Kemm, J. (2000) 'Can health impact assessment fulfil the expectations it raises?', Public Health, 114, pp. 431-433.

Kemm, J., Parry, J. and Palmer, S. (2004) Health impact assessment. Oxford: Oxford University Press.

Kovats, S., Depledge, M., Haines, A., Fleming, L.E., Wilkinson, P., Shonkoff, S.B. and Scovronick, N. (2014) 'The health implications of fracking', The Lancet, 383(9936), pp. 22112212.

Kreiger, G.R., Utzinger, J., Winkler, M.S., Divall, M.J., Phillips, S.D., Balge M.Z. and Singer B.H. (2010) 'Barbarians at the gate: storming the Gothenburg consensus', The Lancet, 375, pp. 2129-2131.

LaBouchardiere, R.A., Goater, S. and Beeton, R.J.S. (2014) 'Integrating stakeholder perceptions of environmental risk into conventional management frameworks: coal seam gas 
development in Queensland', Australasian Journal of Environmental Management, 21(4), pp. 359-377.

Martuzzi, M. and Tickner J.A. (2004) The precautionary principle: protecting public health, the environment and the future of our children. Copenhagen: World Health Organization, Regional Office for Europe.

Martuzzi, M., Cave, B., Nowacki, J., Viliani, F. and Vohra, S. (2014). Health impact assessment. Fastips No. 8. International Association for Impact Assessment.

Milner S.J., Bailey, C., Deans, J. and Pettigrew, D. (2005) 'Integrated impact assessment in the UK - use efficacy and future development', Environmental Impact Assessment Review, 25(1) pp. 47-61.

Morris, P. and Therivel, R. (ed.). (2001). Methods of Environmental Impact Assessment. Spon Press. Oxford.

Palerang Council, Greater Southern Area Heath Service (NSW Health) and University of New South Wales (2006) Bungedore health impact assessment: a rapid health impact assessment of two development scenarios in Bungedore, New South Wales. Center for Health Equity Training, Research and Evaluation.

Parry, J and Stevens, A. (2001) 'Prospective health impact assessment: pitfalls, problems, and possible ways forward', British Medical Journal, 323(7322), pp. 1177-1182.

Peterson, K. (2004) 'The role and value of strategic environmental assessment in Estonia: stakeholders' perspectives', Impact Assessment and Project Appraisal, 22(2), pp. 159-165.

Quigley, R., den Broeder, L., Furu, P., Bond, A., Cave, B. and Bos, R. (2006) Health impact assessment international best practice principles. Special Publication Series No. 5. Fargo, USA: International Association for Impact Assessment.

Quigley, R.J. and Taylor, L.C. (2004) Evaluating health impact assessment, Public Health, 118(8) pp. 544-552.

Ross, C.L., M. Orenstein, M. and Botchwey, N. (2014) Health impact assessment in the United States. New York: Springer-Verlag.

Science and Environmental Health Network, Johnson Foundation, W. Alton Jones Foundation, C.S. Fund and Lowell Center for Sustainable Production, University of Massachusetts-Lowell. 
(1998) Wingspread consensus statement on the precautionary principle: Wingspread Conference on the Precautionary Principle. Johnson Foundation, Racine, 23-25 January. Racine: Science and Environmental Health Network.

Scottish Government (2015) Moratorium on fracking. Available at: http://news.scotland.gov.uk/News/Moratorium-called-on-fracking-1555.aspx (Accessed: 01 May 2016).

Senécal, P., Goldsmith, B., Conover, S., Sadler, B., Brown, K. (1999) Principles of environmental impact assessment best practice. Special Publication Series No. 1. Fargo, USA: International Association for Impact Assessment and Institute of Environmental Assessment.

South Carolina Institute of Public Health (2013) A health impact assessment (HIA) of park, trail, and green space planning in the west side of Greenville, South Carolina.

Thailand Department of Health (2004) The health impact assessment for healthy public policy: a case study of "Garden City Project" Yala City, Thailand. Ministry of Public Health.

United Nations (1992) Report of the United Nations Conference on Environment and Development, Annex 1: Rio Declaration on Environment and Development. Rio de Janeiro, 314 June 1992.

United Nations Economic Commission for Europe (UNECE). (1991). Policies and Systems for Environmental Impact Assessment. Geneva: UNECE.

Vohra S. (2008) Environmental and social determinants of health diagram, adapted from Harris A. Rapid health impact assessment: a guide to research. 2003.

Vohra, S. Cave, B., Viliani, F. Harris-Roxas, B.F. and Bhatia, R. (2010) 'New international consensus on health impact assessment', The Lancet, 375, p. 2010.

Watterson, A. and Dinan, W. (2016). 'Health impact assessments, regulation, and the unconventional gas industry in the UK: exploiting resources, ideology, and expertise?', New Solutions, 25(4), pp. 480-512.

Winkler, M.S., Krieger, G.R., Divall, M.J., Cissé, G., Wielga, M., Singer B.H., Tanner, M. and Utzinger, J. (2013). 'Untapped potential of health impact assessment', Bulletin of the World Health Organization. 91(4), pp. 237-312. 